\title{
Red Blood Cell Transfusions and Iron Therapy for Patients Presenting with Acute Upper Gastrointestinal Bleeding: A Survey of Canadian Gastroenterologists and Hepatologists
}

\author{
Kyle J. Fortinsky, ${ }^{1}$ Myriam Martel, ${ }^{2}$ Roshan Razik, ${ }^{1}$ Gillian Spiegle, ${ }^{1}$ Zane R. Gallinger, ${ }^{1}$ \\ Samir C. Grover, ${ }^{1}$ Katerina Pavenski, ${ }^{3}$ Adam V. Weizman, ${ }^{1}$ Lukasz Kwapisz, ${ }^{4}$ Sangeeta \\ Mehta, ${ }^{5}$ Sarah Gray, ${ }^{6}$ and Alan N. Barkun ${ }^{2,7}$ \\ ${ }^{1}$ Division of Gastroenterology, University of Toronto, Toronto, ON, Canada \\ ${ }^{2}$ Epidemiology and Biostatistics and Occupational Health, McGill University Health Center, McGill University, Montreal, QC, Canada \\ ${ }^{3}$ Division of Hematology and Transfusion Medicine, University of Toronto, Toronto, ON, Canada \\ ${ }^{4}$ Division of Gastroenterology, Western University, London, ON, Canada \\ ${ }^{5}$ Division of Critical Care, University of Toronto, Toronto, ON, Canada \\ ${ }^{6}$ Division of Emergency Medicine, University of Toronto, Toronto, ON, Canada \\ ${ }^{7}$ Division of Gastroenterology, McGill University Health Center, McGill University, Montreal, QC, Canada
}

Correspondence should be addressed to Alan N. Barkun; alan.barkun@muhc.mcgill.ca

Received 23 December 2015; Accepted 17 May 2016

Academic Editor: Geoffrey Williams

Copyright @ 2016 Kyle J. Fortinsky et al. This is an open access article distributed under the Creative Commons Attribution License, which permits unrestricted use, distribution, and reproduction in any medium, provided the original work is properly cited.

\begin{abstract}
Introduction. There is limited data evaluating physician transfusion practices in patients with acute upper gastrointestinal bleeding (UGIB). Methods. A web-based survey was sent to 500 gastroenterologists and hepatologists across Canada. The survey included clinical vignettes where physicians were asked to choose transfusion thresholds. Results. The response rate was $41 \%(N=203)$. The reported hemoglobin (Hgb) transfusion trigger differed by up to $50 \mathrm{~g} / \mathrm{L}$. Transfusions were more liberal in hemodynamically unstable patients compared to stable patients (mean $\mathrm{Hgb}$ of $86.7 \mathrm{~g} / \mathrm{L}$ versus $71.0 \mathrm{~g} / \mathrm{L} ; p<0.001$ ). Many clinicians $(24 \%)$ reported transfusing a hemodynamically unstable patient at a $\mathrm{Hgb}$ threshold of $100 \mathrm{~g} / \mathrm{L}$ and the majority (57\%) are transfusing two units of RBCs as initial management. Patients with coronary artery disease (mean Hgb of $84.0 \mathrm{~g} / \mathrm{L}$ versus $71.0 \mathrm{~g} / \mathrm{L} ; p<0.01$ ) or cirrhosis (mean $\mathrm{Hgb}$ of $74.4 \mathrm{~g} / \mathrm{L}$ versus $71.0 \mathrm{~g} / \mathrm{L} ; p<0.01$ ) were transfused more liberally than healthy patients. Fewer than $15 \%$ would prescribe iron to patients with UGIB who are anemic upon discharge. Conclusions. The transfusion practices of gastroenterologists in the management of UGIB vary widely and more high-quality evidence is needed to help assess the efficacy and safety of selected transfusion thresholds in varying patients presenting with UGIB.
\end{abstract}

\section{Introduction}

The annual incidence of acute upper gastrointestinal bleeding (UGIB) in the United States has been reported as high as 160 per 100,000 adults leading to roughly 300,000 hospital admissions per year $[1,2]$. Approximately $35-40 \%$ of patients presenting to hospital with UGIB are provided at least one red blood cell (RBC) transfusion [3]. In the UK, patients presenting with UGIB are transfused, on average, 1.58 units of RBCs [4]. UGIB accounts for $14 \%$ of all RBC transfusions in the UK [5]. Although the costs and complications of transfusions are well documented, clinicians often feel uncomfortable restricting transfusions, especially in patients with active hemorrhage and in those with significant comorbidities such as cardiac disease $[6,7]$.

Several randomized controlled trials (RCT) have investigated different transfusion strategies in critically ill patients and patients after cardiac and noncardiac surgeries [8-10]. The ideal transfusion threshold in patients presenting with UGIB remains largely unknown and has been studied in only one RCT which found that a more restrictive transfusion strategy may have mortality benefit in certain patients [11]. 
The 2013 American College of Gastroenterology (ACG) guidelines as well as international consensus guidelines suggest that patients with hemoglobin levels $\leq 70 \mathrm{~g} / \mathrm{L}$ should receive blood transfusions to reach a target hemoglobin level of $70-90 \mathrm{~g} / \mathrm{L}$, provided that the individual has no coronary artery disease, evidence of tissue hypoperfusion, or acute hemorrhage $[2,12]$. In patients with acute coronary syndrome, UGIB is associated with a markedly increased mortality, and a higher hemoglobin target level may be advantageous $[2,13]$.

In a 2011 UK audit, $43 \%$ of patients with UGIB received a RBC transfusion despite $73 \%$ presenting with hemoglobin above $80 \mathrm{~g} / \mathrm{L}$ [7]. This audit, however, was performed prior to Villanueva et al.s study that highlighted the benefits of restrictive transfusions [11].

Current international consensus and ACG guidelines on UGIB do not discuss the role of iron replacement therapy $[2,12]$. Only one single centre RCT has evaluated iron replacement in patients after UGIB and found that patients who received iron therapy after UGIB had significantly lower rates of anemia at 3 months compared to placebo (17\% versus $70 \%, p<0.01$ ) [14]. Correcting anemia after UGIB may minimize the need for transfusion during a rebleeding episode. One prospective observational study suggested that patients discharged after UGIB with hemoglobin values $<100 \mathrm{~g} / \mathrm{L}$ had twice the mortality rates when compared to patients with hemoglobin levels $>100 \mathrm{~g} / \mathrm{L}$ [15]. One retrospective study found that only $16 \%$ of anemic patients after UGIB are being prescribed oral iron supplementation upon discharge [16].

High-quality evidence guiding transfusion thresholds and iron therapy in the setting of UGIB is lacking. Many clinicians select transfusion thresholds based on individual patient factors and personal experience. The objectives of the current study were to characterize gastroenterologists' reported transfusion and iron prescribing practices in patients with UGIB. We also explored potential barriers for adopting results from large RCTs and guidelines into clinical practice.

\section{Methods}

2.1. Survey Participants. Responses included Canadian gastroenterologists, hepatologists, and current trainees of accredited Canadian gastroenterology and hepatology training programs. Email addresses of respondents were obtained by contacting institutions and by using publicly available information from institutional websites.

2.2. Survey Design. The survey was created using established methods to ensure optimal performance [17]. Demographics from the respondents were obtained to acquire baseline information regarding clinical expertise, comfort in managing UGIB, and sources of information used to base management approaches. A series of clinical vignettes were then presented with the purpose of determining transfusion thresholds ranging from $50 \mathrm{~g} / \mathrm{L}$ to $120 \mathrm{~g} / \mathrm{L}$. Vignettes varied based upon patient age, comorbidities, presentation of GI bleeding (e.g., melena versus hematemesis), hemodynamic stability, and intravascular volume status (see survey scenarios as follows):
"Below what hemoglobin level would you transfuse red blood cells in this patient?"

Scenario 1 (healthy, hemodynamically stable):

A 50-year-old healthy woman presents with melena and is hemodynamically stable (BP $120 / 80$, HR 65). There is no evidence of a volume deficit on clinical exam.

Scenario 2 (healthy, hemodynamically unstable):

A 50-year-old healthy woman presents with melena and is hemodynamically unstable (BP 90/50, HR 115) with evidence of a volume deficit on clinical exam.

Scenario 3 (cardiovascular disease, hemodynamically stable):

A 50-year-old man with triple vessel coronary artery disease presents with melena and is hemodynamically stable (BP 120/80, HR 65). There is no evidence of a volume deficit on clinical exam. The patient denies having any chest pain or dyspnea, and his ECG and troponin are unremarkable.

Scenario 4 (cardiovascular disease, hemodynamically unstable):

A 50-year-old man with triple vessel coronary artery disease presents with melena and is hemodynamically unstable (BP 90/50, HR 115) and he has ischemic ECG changes and an elevated troponin. He is complaining of mild chest pain and some shortness of breath.

Scenario 5 (warfarin therapy, hemodynamically stable):

A 65-year-old woman with hypertension and atrial fibrillation who is taking warfarin (INR 2.5) presents with melena and is hemodynamically stable (BP 120/80, HR 65). There is no evidence of a volume deficit on clinical exam.

Scenario 6 (warfarin therapy, hemodynamically unstable):

A 65-year-old woman with hypertension and atrial fibrillation who is taking warfarin (INR 2.5) presents with melena and is hemodynamically unstable (BP 90/60, HR 115). There is evidence of a volume deficit on clinical exam and the patient is being resuscitated with intravenous crystalloid.

Scenario 7 (cirrhosis, hemodynamically stable):

A 65-year-old patient with decompensated cirrhosis presents with hematemesis and is hemodynamically stable (BP 100/60, HR 85). There is no evidence of a volume deficit on clinical exam. 
Additional multiple-choice questions assessed the number of units of red blood cells clinicians would transfuse as part of initial management. Further questions investigated the influence of warfarin intake compared to novel anticoagulants on respondents' transfusion thresholds and iron prescription rates for anemic patients after UGIB. We asked about physicians' awareness of current guidelines and potential barriers to adopting results of clinical trials and guidelines into clinical practice. The survey is available for viewing as a supplementary file.

2.3. Survey Distribution. Each potential participant was emailed two separate links to the survey, one in English and one in French. The questionnaire was disseminated using an online platform (https://www.surveymonkey.com/) in April 2015. Two follow-up emails were sent after the initial e-mail to encourage nonresponders at two-week intervals. Upon entering the survey, an introductory paragraph explained the purpose of the study. Participation was voluntary, and the respondent was asked to agree to participate and provide informed consent prior to initiating the survey. Participants were able to stop the survey at any time without penalty. All data was stored anonymously within the SurveyMonkey online database. The McGill University Research and Ethics Board approved the survey.

2.4. Statistical Analyses. Descriptive statistics including means, medians, and standard deviations for continuous variables and proportions with $95 \%$ confidence interval (95\% CI) for categorical variables were used for each question in the survey. Categorical data were analyzed with $\chi^{2}$ test or Fisher's exact test. Continuous data were analyzed with paired $t$-test. A preplanned regression model was performed using baseline characteristics of physicians including age, gender, level of training, years in practice, comfort managing bleeding, and knowledge of current guidelines to determine whether certain factors influenced transfusion practices, whereby $p$ values $<0.05$ were considered statistically significant. All statistical analyses were performed using SAS version 9.3 (SAS Institute, Cary, NC, USA).

\section{Results}

3.1. Baseline Characteristics. The survey was sent electronically to 518 gastroenterologists and hepatologists across Canada. Eighteen (3.5\%) emails were undeliverable and therefore were removed from the database. Of the remaining 500 successfully sent emails, 204 participants entered the survey with 1 respondent not consenting to participate for an overall response rate of $41 \%(203 / 500)$. The majority of respondents $(83.2 \%)$ were practicing staff physicians who, on average, manage approximately 63 cases of UGIB per year. Respondent characteristics are presented in Table 1. The sources of information drawn upon by participants to manage patients with UGIB are listed in Table 2.

3.2. Transfusion Thresholds Based upon Main Clinical Scenarios. For Scenario 1 (hemodynamically stable 50-year-old
TABLE 1: Baseline characteristics of respondents.

\begin{tabular}{|c|c|}
\hline Characteristics & $\begin{array}{l}\text { Respondents, } \%(95 \% \\
\text { CI) }(N=203)\end{array}$ \\
\hline \multicolumn{2}{|l|}{ Survey language } \\
\hline English & $89.8 \%(84.9 \% ; 93.2 \%)$ \\
\hline French & $10.2 \%(6.8 \%-15.2 \%)$ \\
\hline \multicolumn{2}{|l|}{ Age (years) } \\
\hline$<36$ & $32.2 \%(26.0 \% ; 38.7 \%)$ \\
\hline $36-45$ & $36.0 \%(29.7 \% ; 42.8 \%)$ \\
\hline $46-55$ & $14.3 \%(10.1 \% ; 19.8 \%)$ \\
\hline $56-65$ & $11.8 \%(8.1 \% ; 17.0 \%)$ \\
\hline$>65$ & $5.9 \%(3.5 \% ; 11.2 \%)$ \\
\hline Female sex & $29.1 \%(23.3 \% ; 35.7 \%)$ \\
\hline \multicolumn{2}{|l|}{ Province of practice } \\
\hline $\begin{array}{l}\text { Western Canada (Alberta, British } \\
\text { Columbia, Manitoba, and } \\
\text { Saskatchewan) }\end{array}$ & $27.8 \%$ \\
\hline Ontario & $49.8 \%$ \\
\hline Quebec & $16.8 \%$ \\
\hline $\begin{array}{l}\text { Atlantic Canada (New Brunswick, } \\
\text { Newfoundland and Labrador, Nova } \\
\text { Scotia, and Prince Edward Island) }\end{array}$ & $4.6 \%$ \\
\hline Outside of Canada & $1 \%$ \\
\hline \multicolumn{2}{|l|}{ Level of training } \\
\hline Staff GI Physician & $83.2 \%(77.5 \% ; 87.8 \%)$ \\
\hline GI trainee (PGY 4-5) & $8.9 \%(5.7 \% ; 13.6 \%)$ \\
\hline $\begin{array}{l}\text { GI trainee (PGY } 6 \text { or above) retired } \\
\text { physician }\end{array}$ & $\begin{array}{c}6.4 \%(3.8 \% ; 10.7 \%) \\
0.5 \%(0.0 \% ; 2.8 \%) \\
\end{array}$ \\
\hline \multicolumn{2}{|l|}{ Type of center } \\
\hline Academic & $41.9 \%(35.3 \% ; 48.8 \%)$ \\
\hline Community & $27.1 \%(21.5 \% ; 33.6 \%)$ \\
\hline $\begin{array}{l}\text { Combination of academic and } \\
\text { community }\end{array}$ & $13.8 \%(9.7 \% ; 19.2 \%)$ \\
\hline I am not affiliated with a hospital & $0.5 \%(0.0 \% ; 2.8 \%)$ \\
\hline \multicolumn{2}{|l|}{ Comfort managing UGIB } \\
\hline Extremely comfortable & $66.3 \%(59.3 \% ; 72.7 \%)$ \\
\hline Slightly comfortable & $24.6 \%(19.0 \% ; 31.2 \%)$ \\
\hline Extremely uncomfortable & $5.4 \%(2.9 \% ; 9.6 \%)$ \\
\hline Neutral & $3.7 \%(1.8 \% ; 7.5 \%)$ \\
\hline
\end{tabular}

healthy patient with melena), $71 \%$ of clinicians transfused at hemoglobin $(\mathrm{Hgb})$ below 70 (mean: $71.0 \pm 6.4$ ) and 29\% deviated from current guidelines (Figure 1). If the same patient was hemodynamically unstable (Scenario 2), 69.3\% of clinicians would provide a transfusion at Hgb below 90 (mean: $86.7 \pm 11.8$ ). The distribution of transfusion thresholds for the hemodynamically unstable patient varied by up to $60 \mathrm{~g} / \mathrm{L}$ (range: $60 \mathrm{~g} / \mathrm{L}$ to $120 \mathrm{~g} / \mathrm{L}$; see Figure 2). Transfusion thresholds for the two scenarios differed significantly (71.0 versus $86.7 \mathrm{~g} / \mathrm{L}, p<0.001)$.

Patients with coronary artery disease (mean $\mathrm{Hgb} 84.0 \mathrm{~g} / \mathrm{L}$ versus $71.0 \mathrm{~g} / \mathrm{L}, p<0.001$ ) or cirrhosis (mean Hgb $74.4 \mathrm{~g} / \mathrm{L}$ versus $71.0 \mathrm{~g} / \mathrm{L}, p<0.01$ ) were transfused at higher 
TABLE 2: Continuing medical education (CME) used for management of UGIB $(n=203)$.

\begin{tabular}{lc}
\hline \multicolumn{2}{l}{ Type of CME used (each respondent may select multiple choices) } \\
\hline $\begin{array}{l}\text { Medical conferences } \\
\text { Clinical guidelines on UGIB }\end{array}$ & $81.5 \%(76.1 \% ; 86.8 \%)$ \\
management & $69.8 \%(63.4 \% ; 76.1 \%)$ \\
Review articles & $65.4 \%(58.8 \% ; 71.9 \%)$ \\
Primary journal articles & $63.9 \%(57.3 \% ; 70.5 \%)$ \\
Online clinical resources (e.g., up to & $53.2 \%(46.3 \% ; 60.1 \%)$ \\
date) & $49.3 \%(42.4 \% ; 56.2 \%)$ \\
Journal clubs & $30.7 \%(24.4 \% ; 37.1 \%)$ \\
Newsletters (e.g., NEJM journal watch) & $7.8(4.1 \% ; 11.5 \%)$ \\
Online webinars or podcasts & $2.4 \%(1.1 \% ; 5.6 \%)$ \\
Other & $0.5 \%(0.0 \% ; 1.4 \%)$ \\
None &
\end{tabular}

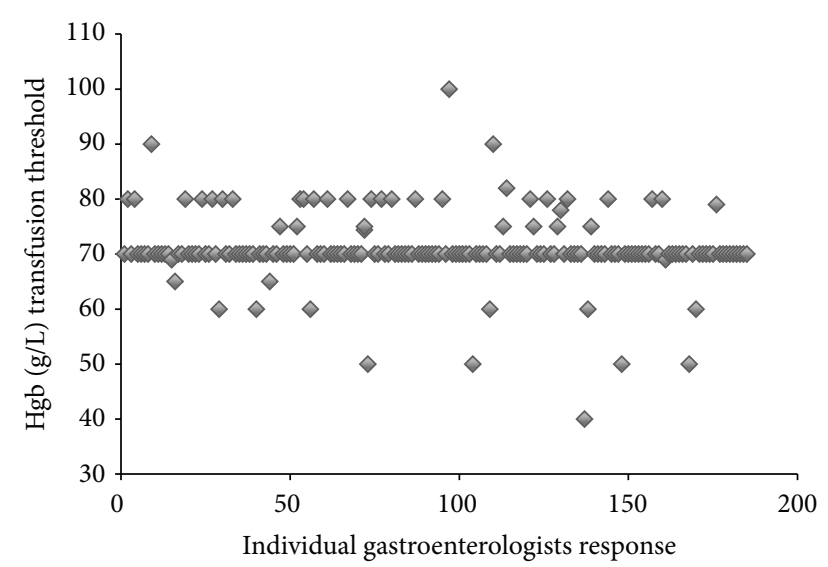

FIGURE 1: Selected hemoglobin transfusion thresholds for a healthy and hemodynamically stable patient with UGIB as described in Scenario 1. Each data point on the figure represents individual respondent's transfusion threshold.

threshold hemoglobin than healthy patients, as were patients on warfarin (mean $\mathrm{Hgb}$ of $75.3 \mathrm{~g} / \mathrm{L}$ versus $71.0 \mathrm{~g} / \mathrm{L}, p<0.001$ ). $15 \%$ ( $95 \%$ CI) of respondents would perform transfusion more liberally if the patients were on dabigatran, rivaroxaban, or apixaban as opposed to warfarin (see Figure 3). Overall, hemodynamically unstable patients were transfused more liberally than hemodynamically stable patients across all scenarios (see Figure 4). For a healthy hemodynamically unstable patient (see survey scenarios in Section 2.2, Scenario 2) $19 \%, 1 \%$, and $3 \%(95 \% \mathrm{CI})$ of clinicians would perform transfusion at hemoglobin threshold of $100 \mathrm{~g} / \mathrm{L}, 110 \mathrm{~g} / \mathrm{L}$, and $120 \mathrm{~g} / \mathrm{L}$, respectively.

3.3. Initial Transfusion Management. Over half of respondents (57\%) reported transfusing 2 units of RBCs as initial management. Most respondents $(56.0 \%(48.4 \%$; $63.4 \%))$ also felt more likely to be held legally responsible for the complications related to "under-transfusing" than the complications associated with "over-transfusing." In a clinical scenario targeting the most appropriate next step in management of

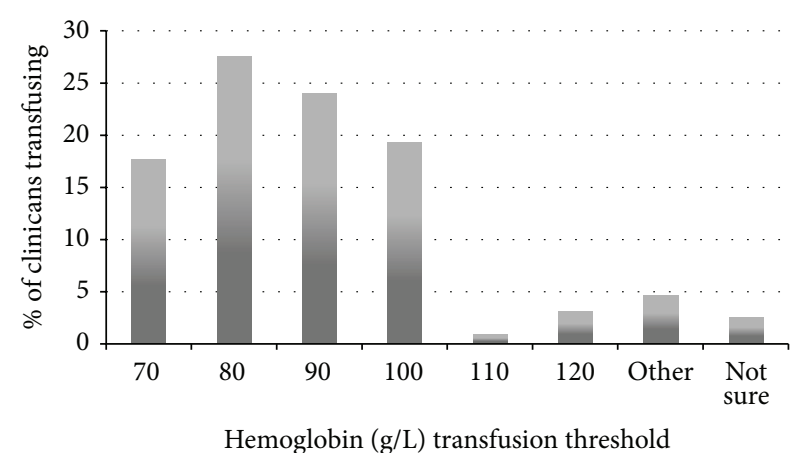

FIGURE 2: Selected hemoglobin transfusion thresholds for a healthy and hemodynamically unstable patient with UGIB as described in Scenario 2.

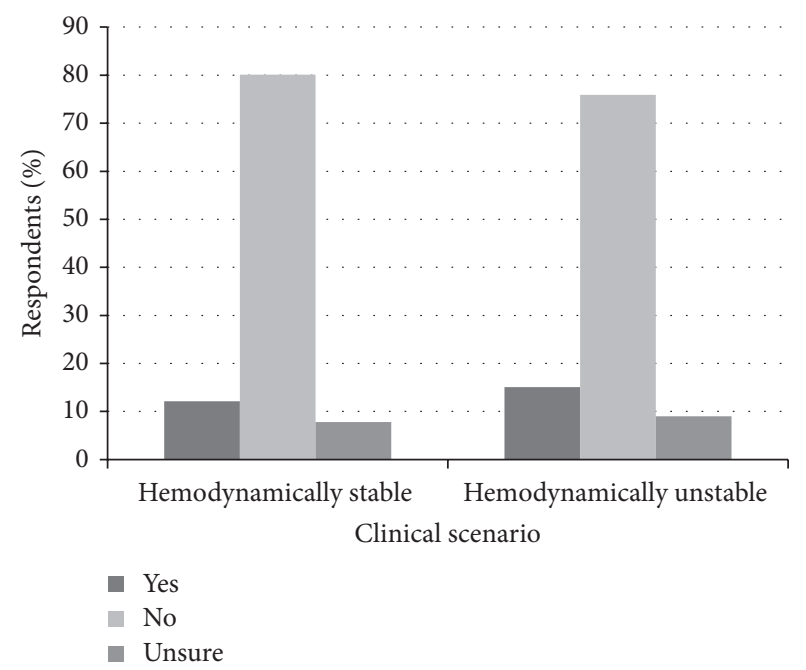

FIGURE 3: Are clinicians transfusing patients with UGIB on novel anticoagulants more liberally than patients on warfarin?

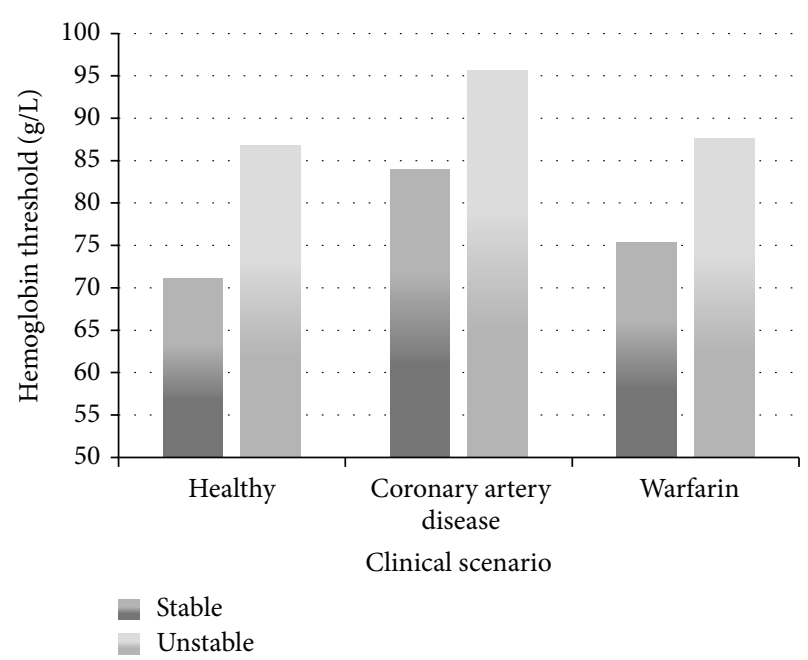

FIGURE 4: Mean hemoglobin transfusion threshold by clinical scenario. 
TABLE 3: Clinicians deciding on the best next step in management of an actively bleeding patient with UGIB (see scenario below).

A 50-year-old healthy patient presents with hematemesis and is hemodynamically unstable (BP 90/50, HR 115) with evidence of a volume deficit on clinical exam. Two large bore IVs were inserted and resuscitation was initiated with intravenous crystalloid. Routine blood work including a CBC and RBC cross-match has been sent. What would be your next steps?

I would hold off on a blood transfusion until I know the hemoglobin level $38.6 \%(31.8 \% ; 46.0 \%)$

I would wait for cross-matched RBCs and transfuse 1-2 units once available $25.0 \%(19.2 \% ; 31.9 \%)$

It depends on how much the patient appears to be bleeding $18.2 \%(13.2 \% ; 24.5 \%)$

I would transfuse 1-2 units of uncross-matched red blood cells STAT

$13.1 \%(8.9 \% ; 18.6 \%)$

It depends on patient's symptoms

$4.6 \%(2.3 \% ; 8.7 \%)$

I would wait for cross-matched RBCs and transfuse 3-4 units once available

$0.6 \%(0.1 \% ; 3.2 \%)$

TABLE 4: Barriers to evidence-based practice.

NEJM Study: Why has this study NOT changed your transfusion practice? Choose as many as apply.

My current practice was already in line with the conclusions of this study

$59.4 \%(41.4 \% ; 77.4 \%)$

There can never be a "strict" transfusion cutoff; need a case-by-case basis

$50.0 \%(31.7 \% ; 68.3 \%)$

The protocol in the study was not usual practice (i.e., endoscopy within 6 hours)

$43.8 \%(25.6 \% ; 61.9 \%)$

More studies are required

$28.1 \%(11.7 \% ; 44.6 \%)$

I wouldn't change my practice based on a single study

$25.0 \%(9.1 \% ; 40.9 \%)$

The study was based out of a single center

$12.5 \%(0.4 \% ; 24.6 \%)$

My patients are significantly different than those in the study

$9.4 \%(0.0 \% ; 20.1 \%)$

I don't agree with the study analysis and/or conclusions

$6.3 \%(0.0 \% ; 15.1 \%)$

Other

$1.4 \%(0.4 \% ; 4.9 \%)$

I will never feel comfortable with restrictive transfusion

$0.0 \%$

International Consensus Guidelines

Why do you NOT agree with these proposed transfusion thresholds? Choose as many as apply.

Using strict cut-offs prevents using clinical judgement

$73.7 \%(59.0 \% ; 88.4 \%)$

There is insufficient high quality evidence to support the cut-offs

$36.8 \%(20.8 \% ; 52.9 \%)$

I was not aware of these cut-offs

$7.9 \%(0.0 \% ; 16.9 \%)$

Patient outcomes are better with more liberal transfusion thresholds

$5.3 \%(0.0 \% ; 12.7 \%)$

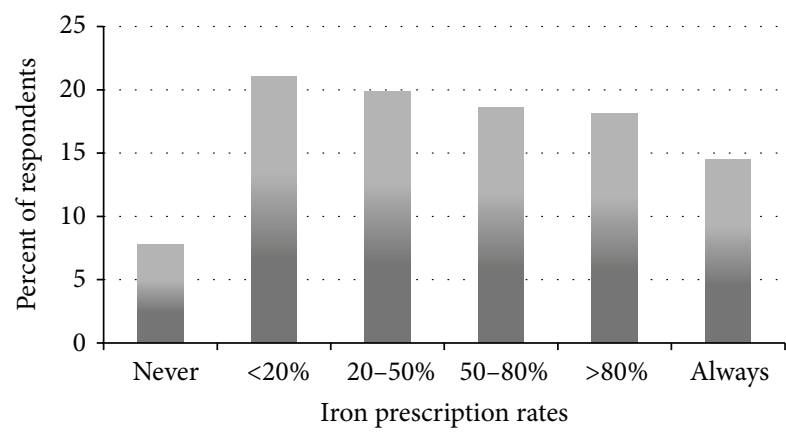

Figure 5: The percentage of clinicians who prescribe iron therapy to anemic patients after upper gastrointestinal bleeding.

an actively bleeding patient with UGIB, responses were highly varied with $38.6 \%$ (31.8-46.0\%) awaiting an initial Hgb level to decide on a transfusion strategy (Table 3).

3.4. Iron Replacement Therapy. Few gastroenterologists $(14.5 \%, 9.9 \% ; 20.6 \%)$ stated they routinely prescribe iron to patients with UGIB who are anemic at discharge (Figure 5).
Most of these clinicians reported prescribing oral iron (81.3\% (74.7\%; 86.5\%)) while very few are prescribing intravenous iron $(5.4 \%(2.9 ; 10.0 \%))$.

3.5. Adherence to Current Evidence and Guidelines. The majority of respondents were aware of the large RCT investigating transfusion thresholds in UGIB (92.2\% (87.1\%; $95.4 \%)$ ) as well as existing international consensus guidelines endorsed and disseminated by the Canadian Association of Gastroenterology on UGIB (71.1\% (63.8\%; 77.4\%)). However, roughly a quarter of these clinicians $(22.9 \%(17.2 \% ; 30.0 \%))$ have not changed their transfusion practices based on either publication. Table 4 shows potential barriers for adopting the results and recommendations from both the RCT and guidelines. Most gastroenterologists $(60.8 \%(53.3 \%$; 67.9\%)) have never received formal education on transfusions in UGIB, and almost all $(86.8 \%(80.8 \%$; $91.1 \%))$ feel an educational program or guideline would be useful.

3.6. Predictors of Transfusion Thresholds. The multivariate analysis did not reveal significant predictors of transfusion 
thresholds from possible preplanned candidate prognosticators.

\section{Interpretation}

There is wide variation in the transfusion thresholds amongst gastroenterologists and hepatologists managing patients with UGIB [7]. Even in a healthy and hemodynamically stable patient presenting with UGIB, a setting with the most explicit and agreed-upon guidelines, there were differences in transfusion thresholds of up to $60 \mathrm{~g} / \mathrm{L}$ (threshold range from $40 \mathrm{~g} / \mathrm{L}$ to $100 \mathrm{~g} / \mathrm{L})[2,12]$. Moreover, nearly $20 \%(95 \% \mathrm{CI})$ of clinicians perform transfusion more liberally than suggested by current guidelines (see Figure 1).

Respondents in the current study reported transfusing healthy and hemodynamically stable patients at a lower $\mathrm{Hgb}$ threshold than previous studies $(71 \mathrm{~g} / \mathrm{L}$ versus $77 \mathrm{~g} / \mathrm{L}$ ) [7]. Similar findings were noted in hemodynamically stable cirrhotic patients ( $74 \mathrm{~g} / \mathrm{L}$ versus $85 \mathrm{~g} / \mathrm{L}$ ) [7]. The trend towards a more restrictive transfusion strategy may relate to the RCT by Villanueva et al. that showed a mortality benefit with restrictive transfusions, particularly in cirrhotic patients, possibly because blood transfusions may increase portal pressures and bleeding [11]. Indeed, 78\% of respondents in our survey reported that their transfusion practices changed based on the results of this landmark trial in 2013.

The majority of clinicians (57\%) report transfusing two units of RBCs as their initial management in a patient with UGIB. While one RBC unit can raise the Hgb by $10 \mathrm{~g} / \mathrm{L}$, one study found that this Hgb rise might be even greater in anemic patients $[18,19]$. Only $10-15 \%$ of respondents were more liberal in transfusing a patient on a novel oral anticoagulant when compared to warfarin. One explanation for this finding may be the recent introduction of idarucizumab, an antidote for dabigatran [20].

Consistent with current guidelines, gastroenterologists seem to be more liberal in their transfusions when patients have underlying cardiac disease or present with signs of hemodynamic instability or volume depletion. One quarter (24\%) of respondents reported transfusing a hemodynamically unstable patient at $\mathrm{Hgb}$ threshold of $<100 \mathrm{~g} / \mathrm{L}$, while twice as many clinicians (50\%) would perform transfusion at that same threshold if the patient also had cardiovascular disease.

The only three RCTs that have examined restrictive transfusions in patients with cardiovascular disease have excluded patients with gastrointestinal bleeding $[8,9,21]$. Villanueva et al.s study excluded hemodynamically unstable patients and patients with underlying vascular disease. As such, evidence guiding transfusion management in these subsets of patients is lacking. Certain clinicians might believe that specific patients such as those with hemodynamic instability or cardiac disease may benefit from more liberal transfusions as such patients have not been accurately represented in the available literature.

Another possibility is that liberal transfusions may be a sign of "defensive medicine" whereby physicians act in a way to minimize legal liability [22]. In our study, 56\% of respondents felt that they were more likely to be held legally responsible for the complications related to "undertransfusing" than the complications associated with "overtransfusing." There are, however, dangerous consequences to overtransfusing patients including an increased risk of rebleeding and mortality as well as adverse transfusion reactions including anaphylactic reactions, transfusion-related circulatory overload, and transfusion-related acute lung injury $[6,8,9,11,23-25]$.

The current study represents the fourth study to investigate the use of iron therapy in UGIB $[14,16,26]$. Less than $15 \%$ of respondents are consistently prescribing iron to anemic patients after UGIB, despite a recent RCT that found that iron therapy improves 28-day Hgb levels in anemic patients after UGIB [14].

A prospective, observational study would be the optimal environment for studying transfusion practices in UGIB. The previous UK survey found results that were slightly different compared to a national audit $[7,25,27]$. As such, it is possible that the data collected in our study does not accurately represent the true behavior of our respondents. An observational study, however, would not permit the examination of a large cohort of physicians across an entire country, which is what our survey accomplished. Furthermore, although a higher response rate is always preferable, it is unlikely that a larger sample size would have altered the results towards less heterogeneity in terms of transfusion practices. A previous study found that more recent graduates were more likely more restrictive in their transfusions which we were unable to confirm or refute [7]. It is possible that we were underpowered to detect this difference or that Villanueva et al.'s [11] study altered our respondents' practice.

Approximately 25\% of Canadian gastroenterologists are not following current guidelines and are overtransfusing healthy and hemodynamically stable patients with UGIB. Over $97 \%$ of respondents are interested in an educational program or guideline to address transfusions in UGIB and $86 \%$ of respondents believe that such a program or guideline would change their management. Undoubtedly, the complexity of patient presentations with UGIB demands an individualized approach to transfusion management. Additional studies are needed to determine the effectiveness of iron therapy in UGIB and the safety of restrictive transfusion strategies in hemodynamically unstable patients and those with cardiac disease. More high-quality evidence will help to update guidelines to help reduce practice heterogeneity and improve patient outcomes [28].

\section{Ethical Approval}

This study was approved through the Research and Ethics Board at McGill University.

\section{Competing Interests}

None of the authors have any competing interests. 


\section{Authors' Contributions}

Kyle J. Fortinsky, Myriam Martel, Roshan Razik, Zane R. Gallinger, Samir C. Grover, Katerina Pavenski, Adam V. Weizman, Lukasz Kwapisz, Sangeeta Mehta, Sarah Gray, and Alan N. Barkun all contributed substantially to the conception and design of the study. Kyle J. Fortinsky, Myriam Martel, Gillian Spiegle, and Alan N. Barkun analyzed and interpreted the data. Kyle J. Fortinsky, Myriam Martel, Roshan Razik, Gillian Spiegle, and Alan N. Barkun drafted the paper. All authors critically revised the paper and provided approval of the completed paper. All authors have agreed to act as guarantors of the work.

\section{References}

[1] L. A. Button, S. E. Roberts, P. A. Evans et al., "Hospitalized incidence and case fatality for upper gastrointestinal bleeding from 1999 to 2007: a record linkage study," Alimentary Pharmacology and Therapeutics, vol. 33, no. 1, pp. 64-76, 2011.

[2] A. N. Barkun, M. Bardou, E. J. Kuipers et al., "International consensus recommendations on the management of patients with nonvariceal upper gastrointestinal bleeding," Annals of Internal Medicine, vol. 152, no. 2, pp. 101-113, 2010.

[3] M. Aquarius, F. G. M. Smeets, H. W. Konijn et al., "Prospective multicenter validation of the Glasgow Blatchford bleeding score in the management of patients with upper gastrointestinal hemorrhage presenting at an emergency department," European Journal of Gastroenterology and Hepatology, vol. 27, no. 9, pp. 1011-1016, 2015.

[4] H. E. Campbell, E. A. Stokes, D. Bargo et al., "Costs and quality of life associated with acute upper gastrointestinal bleeding in the UK: cohort analysis of patients in a cluster randomised trial," BMJ Open, vol. 5, no. 4, Article ID e007230, 2015.

[5] J. P. Wallis, A. W. Wells, and C. E. Chapman, "Changing indications for red cell transfusion from 2000 to 2004 in the North of England," Transfusion Medicine, vol. 16, no. 6, pp. 411417, 2006.

[6] L. T. Goodnough, "Risks of blood transfusion," Critical Care Medicine, vol. 31, no. 12, supplement, pp. S678-S686, 2003.

[7] V. Jairath, B. C. Kahan, R. F. A. Logan, S. P. L. Travis, K. R. Palmer, and M. F. Murphy, "Red blood cell transfusion practice in patients presenting with acute upper gastrointestinal bleeding: a survey of 815 UK clinicians," Transfusion, vol. 51, no. 9, pp. 1940-1948, 2011.

[8] P. C. Hébert, G. Wells, M. A. Blajchman et al., "A multicenter, randomized, controlled clinical trial of transfusion requirements in critical care," The New England Journal of Medicine, vol. 340, no. 6, pp. 409-417, 1999.

[9] J. L. Carson, M. L. Terrin, H. Noveck et al., "Liberal or restrictive transfusion in high-risk patients after hip surgery," The New England Journal of Medicine, vol. 365, no. 26, pp. 2453-2462, 2011.

[10] G. J. Murphy, K. Pike, C. A. Rogers et al., "Liberal or restrictive transfusion after cardiac surgery," The New England Journal of Medicine, vol. 372, no. 11, pp. 997-1008, 2015.

[11] C. Villanueva, A. Colomo, and A. Bosch, "Transfusion for acute upper gastrointestinal bleeding," The New England Journal of Medicine, vol. 368, no. 14, pp. 1362-1363, 2013.
[12] L. Laine and D. M. Jensen, "Management of patients with ulcer bleeding," American Journal of Gastroenterology, vol. 107, no. 3, pp. 345-361, 2012.

[13] A. Shalev, D. Zahger, V. Novack et al., "Incidence, predictors and outcome of upper gastrointestinal bleeding in patients with acute coronary syndromes," International Journal of Cardiology, vol. 157, no. 3, pp. 386-390, 2012.

[14] P. Bager and J. F. Dahlerup, "Randomised clinical trial: oral vs. intravenous iron after upper gastrointestinal haemorrhage-a placebo-controlled study," Alimentary Pharmacology \& Therapeutics, vol. 39, no. 2, pp. 176-187, 2014.

[15] T. A. Rockall, R. F. A. Logan, H. B. Devlin, and T. C. Northfield, "Risk assessment after acute upper gastrointestinal haemorrhage," Gut, vol. 38, no. 3, pp. 316-321, 1996.

[16] P. Bager and J. F. Dahlerup, "Lack of follow-up of anaemia after discharge from an upper gastrointestinal bleeding centre," Danish Medical Journal, vol. 60, no. 3, Article ID A4583, 2013.

[17] K. Kelley, B. Clark, V. Brown, and J. Sitzia, "Good practice in the conduct and reporting of survey research," International Journal for Quality in Health Care, vol. 15, no. 3, pp. 261-266, 2003.

[18] J. I. Elizalde, J. Clemente, J. L. Marín et al., "Early changes in hemoglobin and hematocrit levels after packed red cell transfusion in patients with acute anemia," Transfusion, vol. 37, no. 6, pp. 573-576, 1997.

[19] A. M. Naidech, M. J. Kahn, W. Soong, D. Green, H. H. Batjer, and T. P. Bleck, "Packed red blood cell transfusion causes greater hemoglobin rise at a lower starting hemoglobin in patients with subarachnoid hemorrhage," Neurocritical Care, vol. 9, no. 2, pp. 198-203, 2008.

[20] C. V. Pollack, P. A. Reilly, J. Eikelboom et al., "Idarucizumab for dabigatran reversal," The New England Journal of Medicine, vol. 373, no. 6, pp. 511-520, 2015.

[21] B. C. Reeves, C. A. Rogers, and G. J. Murphy, "Liberal or restrictive transfusion after cardiac surgery," The New England Journal of Medicine, vol. 373, no. 2, article 193, 2015.

[22] M. Panella, F. Leigheb, C. Rinaldi, C. Donnarumma, Q. Tozzi, and F. Di Stanislao, "Defensive medicine: defensive medicine: overview of the literature," Igiene e Sanità Pubblica, vol. 71, no. 3, pp. 335-351, 2015.

[23] S. D. Blair, S. B. Janvrin, C. N. McCollum, and R. M. Greenhalgh, "Effect of early blood transfusion on gastrointestinal haemorrhage," British Journal of Surgery, vol. 73, no. 10, pp. 783-785, 1986.

[24] S. A. Hearnshaw, R. F. A. Logan, K. R. Palmer, T. R. Card, S. P. L. Travis, and M. F. Murphy, "Outcomes following early red blood cell transfusion in acute upper gastrointestinal bleeding," Alimentary Pharmacology and Therapeutics, vol. 32, no. 2, pp. 215-224, 2010.

[25] S. A. Hearnshaw, R. F. A. Logan, D. Lowe, S. P. L. Travis, M. F. Murphy, and K. R. Palmer, "Acute upper gastrointestinal bleeding in the UK: patient characteristics, diagnoses and outcomes in the 2007 UK audit," Gut, vol. 60, no. 10, pp. 13271335, 2011.

[26] O. Schröder, M. Schrott, I. Blumenstein, J. Jahnel, A. U. Dignass, and J. Stein, "A study for the evaluation of safety and tolerability of intravenous high-dose iron sucrose in patients with iron deficiency anemia due to gastrointestinal bleeding," Zeitschrift fur Gastroenterologie, vol. 42, no. 8, pp. 663-667, 2004.

[27] J. W. Peabody, J. Luck, P. Glassman et al., "Measuring the quality of physician practice by using clinical vignettes: a prospective validation study," Annals of Internal Medicine, vol. 141, no. 10, pp. 771-780, 2004. 
[28] F. Kanwal, A. Barkun, I. M. Gralnek et al., "Measuring quality of care in patients with nonvariceal upper gastrointestinal hemorrhage: Development of an explicit quality indicator set," The American Journal of Gastroenterology, vol. 105, no. 8, pp. 1710-1718, 2010. 


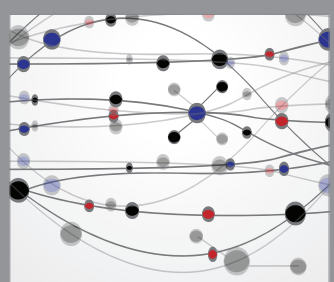

The Scientific World Journal
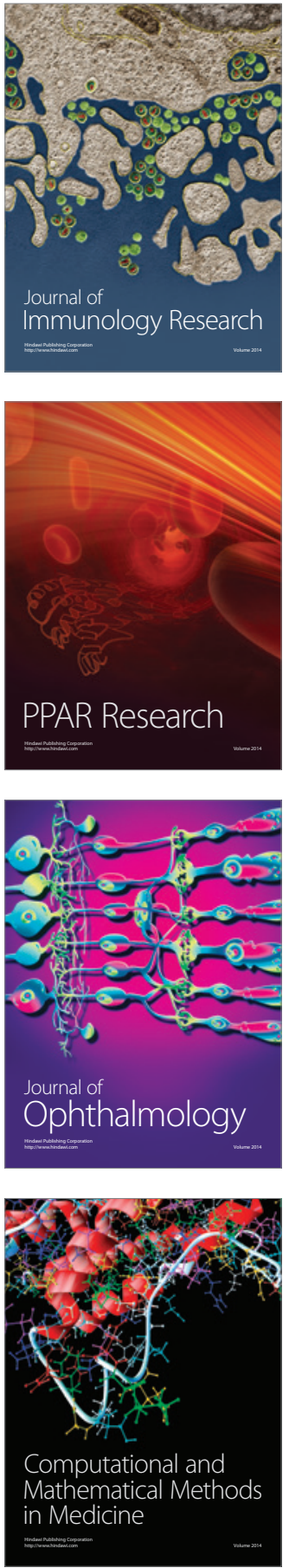

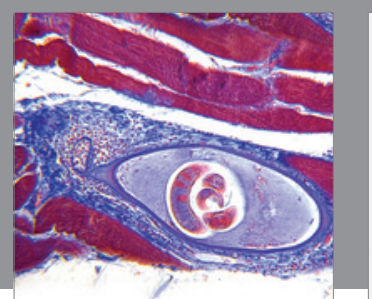

Gastroenterology Research and Practice

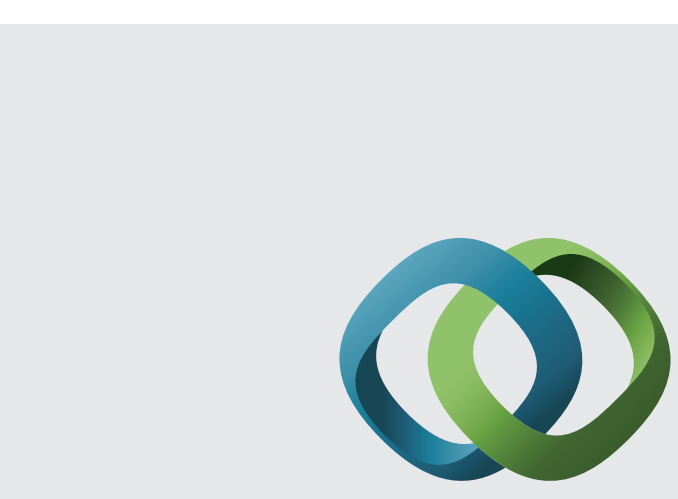

\section{Hindawi}

Submit your manuscripts at

http://www.hindawi.com
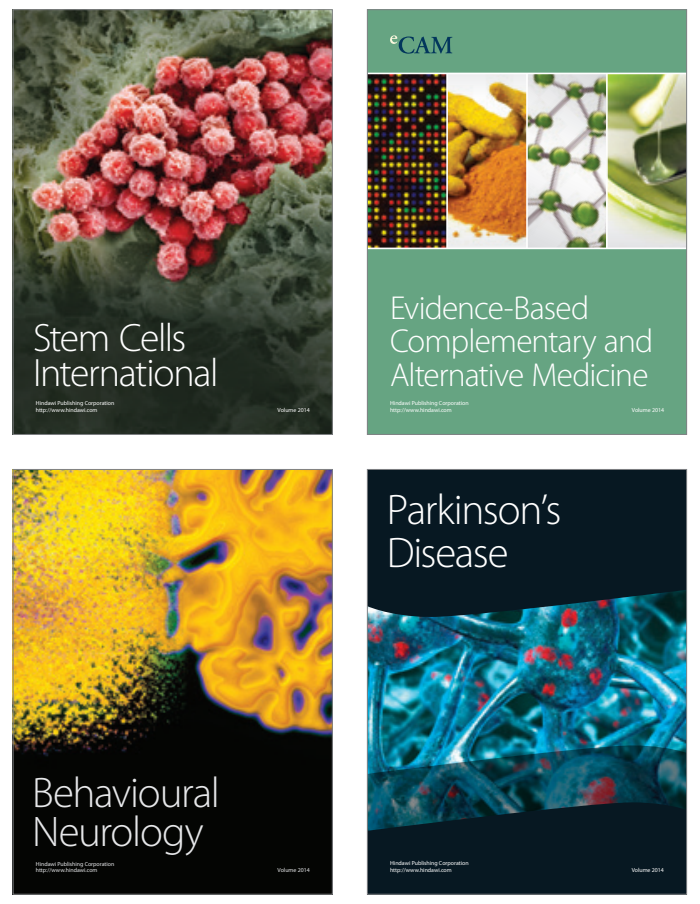
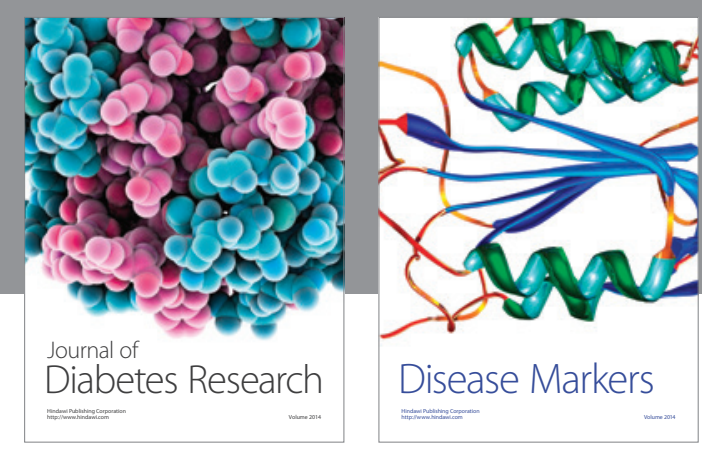

Disease Markers
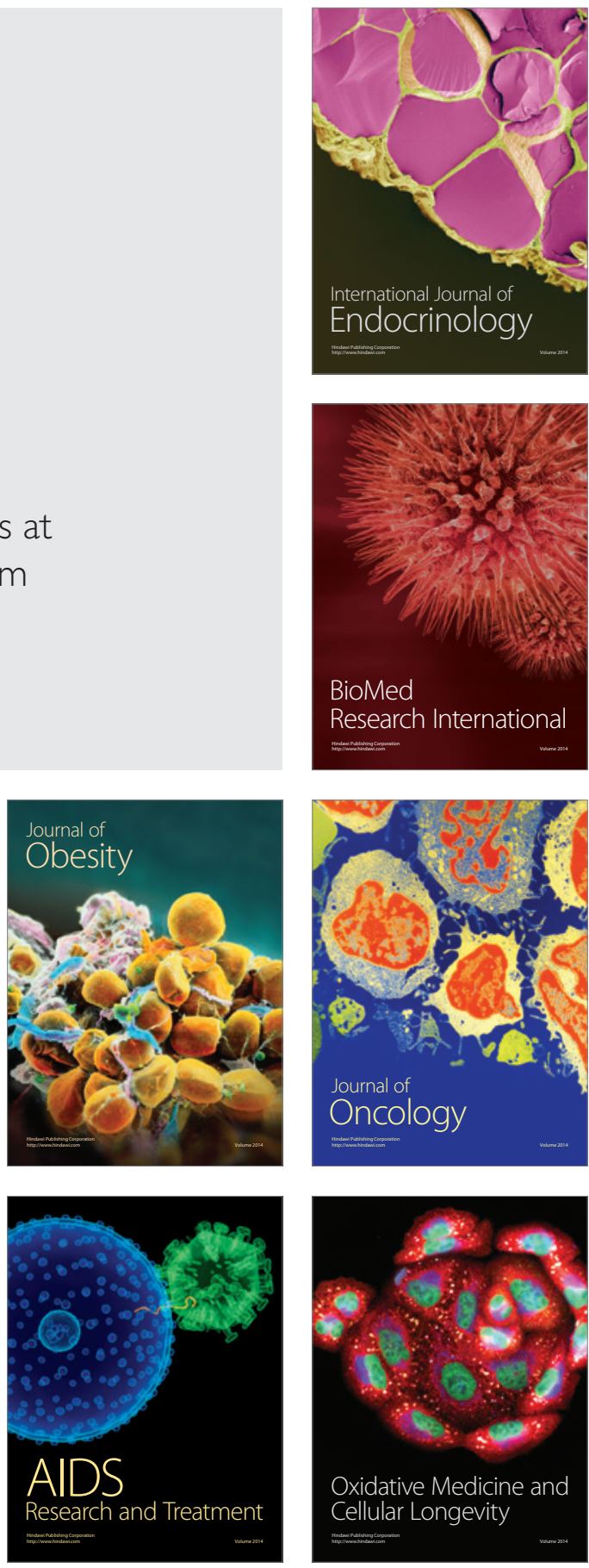